\title{
Mitigating effect of embankment to adjacent pipe with CDM columns
}

\author{
Tiep Duc Pham ${ }^{1}$, Nang Duc Bui ${ }^{1 *}$, Quang Trong Vu ${ }^{1}$, Huan Thanh Duong ${ }^{2}$, and Hieu Chi \\ Phan $^{1}$ \\ ${ }^{1}$ Le Quy Don Technical University, 236 Hoang Quoc Viet, Hanoi, Vietnam \\ ${ }^{2}$ Faculty of Engineering, Vietnam National University of Agriculture, Gia Lam, Hanoi, Vietnam
}

\begin{abstract}
Pipelines are valuable infrastructures that covering a large area or expanding to long distance for the transporting function. This leads to the variety of loads and effects applied on such buried structures. A thread to pipeline integrity is the construction of the embankment on the soft soil which leads to the displacement of the pipe adjacent to the slope. This displacement will effect to the increase of internal force or causing failure of the near-by pipes. The use of concrete pile to improve the soil properties may be a solution; however, the cost for this is expensive. To propose an alternative solution for the problem, this study uses a system of cement deep mixing, CDM, columns as the solution for protecting the pipe. A simple 2D Finite Element, FE, model using Plaxis software has been established based on the equivalent soil approach which considering the CDM columns and their surrounding soil as an unified soil. The effectiveness of the proposed solution has been numerically investigated and proven. The lateral displacement of pipe and the maximum ring bending moment and other internal forces are significantly reduced with the appearance of the CDM columns. The selective parametric study has been implemented revealing the critical input variables are the distance of pipe to the slope and the length of the CDM column.
\end{abstract}

\section{Introduction}

Pipelines, which designed to transport materials such as water, waste water or oil and gas, are systems covering a large area or expanding a long distance. These lead to the increase of the risk of suffering from various adverted soil-related phenomena. Some of them are: crossing the ground faults [1], [2], land sliding [3, 4], tunnel constructing [5], [6] or deformation of the soil due to the appearance of the embankment [7], [8], [9].

Among these threads, the use of embankment on soft soil is recorded as a significant reason for failure to be occurred, which needs reinforcement for the natural soil. For instance, Hong et al. in [7] has reported the experiments that the lateral displacement of pipe can be up to $200 \mathrm{~mm}$ after 30 days. The reinforcement using columns in the soft soil thus proposed as the solution for mitigated approach. Analogously, Huang et al. in [8] recorded a larger than $200 \mathrm{~mm}$ vertical settlement on the surface of soft soil with the

* Corresponding author: ducnangbui@lqdtu.edu.vn 
reinforcement from concrete columns. Reinforcement using concrete is also the commonly choice in such cases [7], [8], [9]. Besides, the appearance of the displacement of pipe will lead to the well-known ring bending force which is widely recorded as the cause of curriculum stress increase [10], decrease of safe factor [11] and coupling with in-plane bending to reach much higher equivalent stress in pipe [12].

Consequently, properties of soft soil under the embankment should be improved. The use of cement deep mixing techniques, CDM, has the capacity of improving the load bearing capacity of soft soil as an economical approach[13], [14], [15]. However, it is rarely seen an investigation of the effectiveness of the CDM columns as the protection for the adjacent pipelines commonly installed near the toe of the slope of the embankment. This study will focus in this investigation and be organized in 4 sections: section 1 is the introduction; section 2 is the establishment of the pipe-soil-embankment-CDM columns system and its Finite Element model, FE; section 3 is the numerical study and the final section is the conclusion.

\section{Finite Element Establishment}

Fig. 1 provides the sketch of the concerned problem where an embankment with the height $\mathrm{H}$, width on top, $\mathrm{B}$ and width at the surface soil $\mathrm{B}+2 \mathrm{a}$. A pipe is installed at $\mathrm{L}_{\mathrm{p}}$ distance from the toe of the slope (point $A$ ) and buried $h_{p}$ from the surface of the soft soil. Pipe dimensions are outside diameter D and wall thickness t. The CDM columns are installed within the ABCD rectangular. Center-to-center distances among columns are equal and denoted as L.

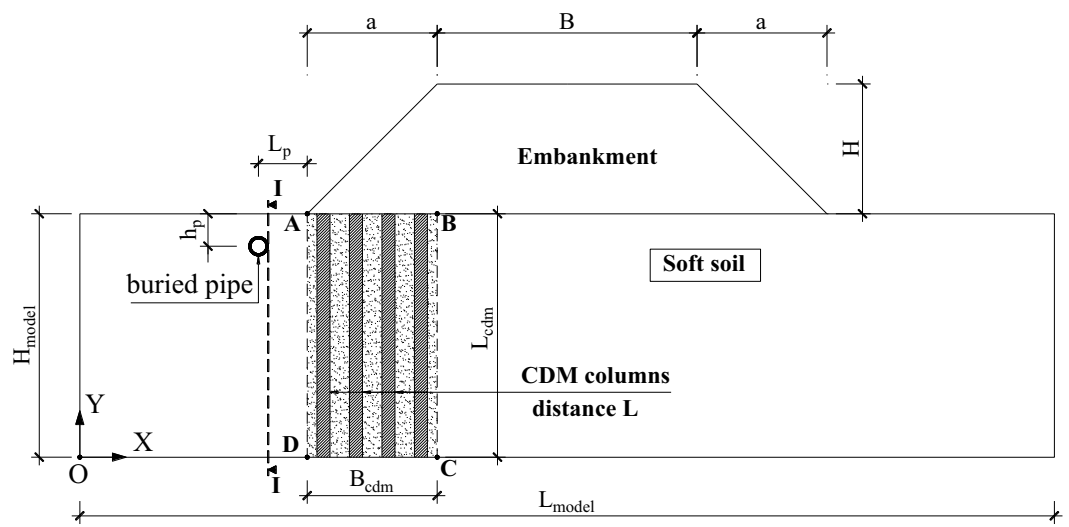

Fig. 1. Scheme of using CDM column to mitigate the deformation of pipe buried in soft soils under the embankment.

For the simplicity purpose, the equivalent soil is proposed, presenting for the simultaneous appearance of CDM columns and their surrounding soft soil. The length and width of such virtual soil are designated as $\mathrm{L}_{\mathrm{cdm}}$ and $\mathrm{B}_{\mathrm{cdm}}$, respectively. The properties of the equivalent soil are found from these of CDM columns and soft soil as guided in Eq.1 and [16].

$$
\begin{aligned}
& \varphi_{e q}=m \cdot \varphi_{c d m}+(1-m) \cdot \varphi_{s} \\
& C_{e q}=m \cdot C_{c d m}+(1-m) \cdot C_{s} \\
& E_{e q}=m \cdot E_{c d m}+(1-m) \cdot E_{s}
\end{aligned}
$$

Where: $\mathrm{m}$ is the ratio of column section area per plan area of equivalent soil block. 


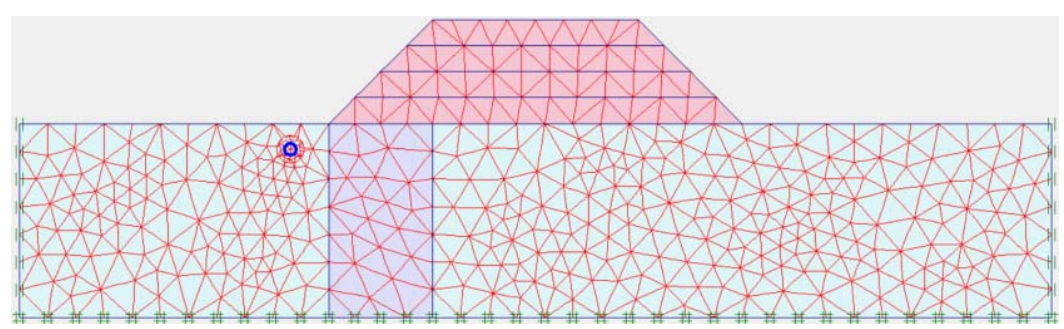

Fig. 2. FE model and the meshing system.

Along with properties of such equivalent soil, properties of embankment and pipe composing the material properties for the FE model are: unit weight, $\gamma$; internal friction angle, $\varphi$; and cohesions, C; deformation modulus, E. The 2D FE model in Plaxis software showed in Fig. 2 with the boundaries of the model are height, $\mathrm{H}_{\text {model }}$, and length, $\mathrm{L}_{\text {model }}$, of the soft soil and set at $15 \mathrm{~m}$ and $80 \mathrm{~m}$, respectively. Element type for soil and embankment is the 15-node triangular [17]. The buried pipe is assigned as the beam type elements. Distribution of the elements and constrains along the boundaries of the model are also illustrated in Fig.2.

\section{Numerical study}

\subsection{The control case}

The scheme of the problem including the main components (i.e. embankment, soft soil, pipe and system of CDM columns) and their critical dimensions are given in Fig.3. Besides, Table 1 provides the information on the properties of embankment, soft soil, CDM column and the equivalent soil.

The CDM columns have the outside diameter $\mathrm{D}=800 \mathrm{~mm}$, allocated in the zigzag shape with $\mathrm{L}=2 \mathrm{~m}$ and the cement content is $300 \mathrm{~kg} / \mathrm{m}^{3}$. The $\mathrm{m}$ ratio $\mathrm{m}=0.1257$. The properties of equivalent soil accounting to the appearance of CDM columns in soft soil, corresponding to the given $\mathrm{m}$ [18], are given in Table 1.

The pipe is made of steel with Elastic modulus $E=2 \times 10^{8} \mathrm{kN} / \mathrm{m}^{2}$ and the dimensions are: outside diameter $\mathrm{D}=914.4 \mathrm{~mm}$; wall thickness, $\mathrm{t}=12.7 \mathrm{~mm}$. This component is buried at the depth of $h_{p}=2 \mathrm{~m}$ and $L_{p}=3 \mathrm{~m}$.

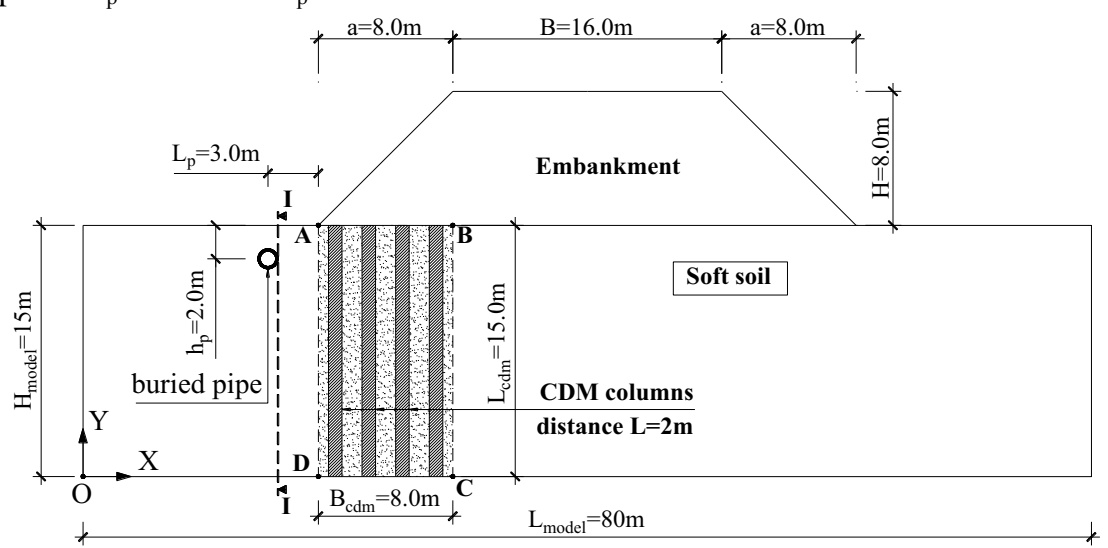

Fig. 3. Inputs of the control case 
Table 1. Properties of soils in the observation

\begin{tabular}{|l|c|c|c|c|}
\hline \multicolumn{1}{|c|}{ Type of soil } & $\begin{array}{c}\gamma \\
(\mathrm{kN} / \mathrm{m} 3)\end{array}$ & $\begin{array}{c}\varphi \\
(\text { Degree })\end{array}$ & $\begin{array}{c}\mathrm{c} \\
(\mathrm{kPa})\end{array}$ & $\begin{array}{c}\mathrm{E} \\
(\mathrm{kPa})\end{array}$ \\
\hline Embankment & 19 & 40 & 1 & 30000 \\
\hline Soft soil & 16,50 & 15 & 10 & 2055 \\
\hline CDM column & & 40 & 70 & 25000 \\
\hline Equivalent soil & & 18,14 & 17,54 & 4938 \\
\hline
\end{tabular}

\subsection{The pipe-soils system interaction}

With the inputs provided in the previous section, the 2D FE model has been developed to model the embankment on soft soil reinforced by CDM columns using the triangular plane element type. The soil material model in this study is the well-known Mohr - Coulomb model, which will be interacted with the Newton Raphson method for figuring out the solution of the nonlinear equations.

The distribution of the plastically deformed points is given in the Fig.3a and $b$ for the cases of without and with CDM column, respectively. It can be seen in Fig.3a that the plastic points tend to locate far away from the pipe causing the asymmetrical of the problem for the case of absenting the CDM columns due to the significant different of stiffness of pipe versus surrounding soil. Meanwhile, the appearance of CDM columns causes the redistribution with fewer plastic locations appears within the pipe and CDM column areas.

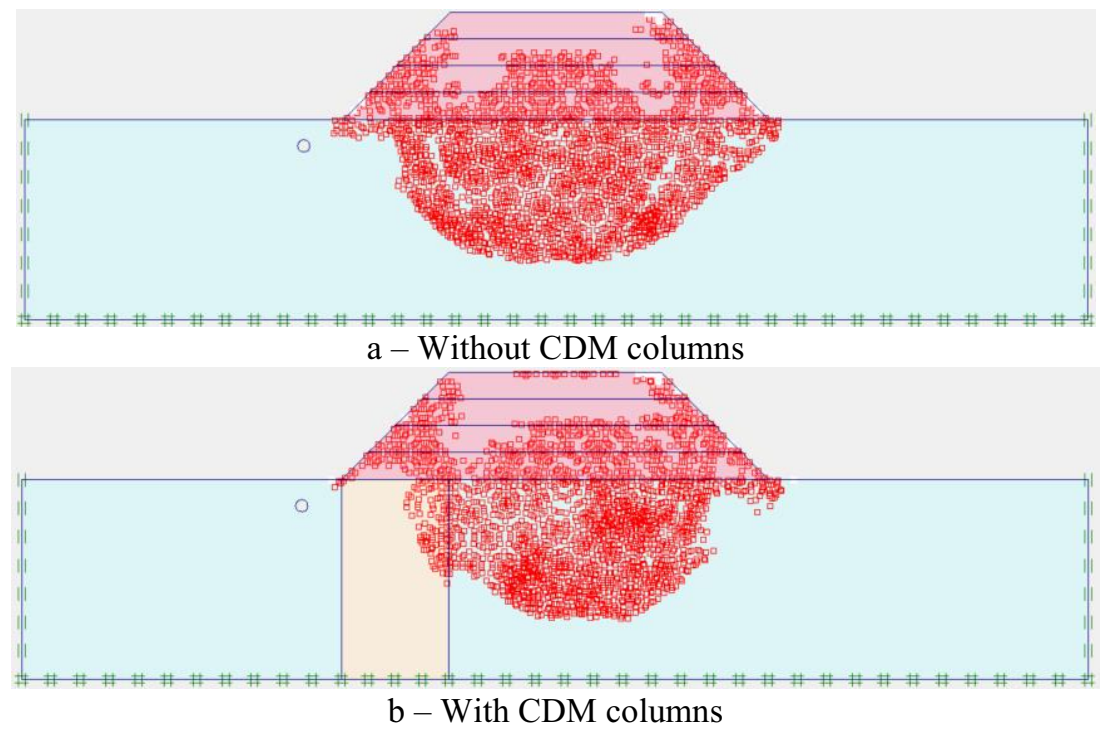

Fig. 4. Distribution of the plastic deformation

Observation on the adjustment of the plastic domains in Fig.4 is reinforced by the displacement contour plot in Fig.5. Compared to the un-reinforced soft soil in Fig.5a, the displacement in Fig. 5b tends to lean forward the right where the pipe is absence. 

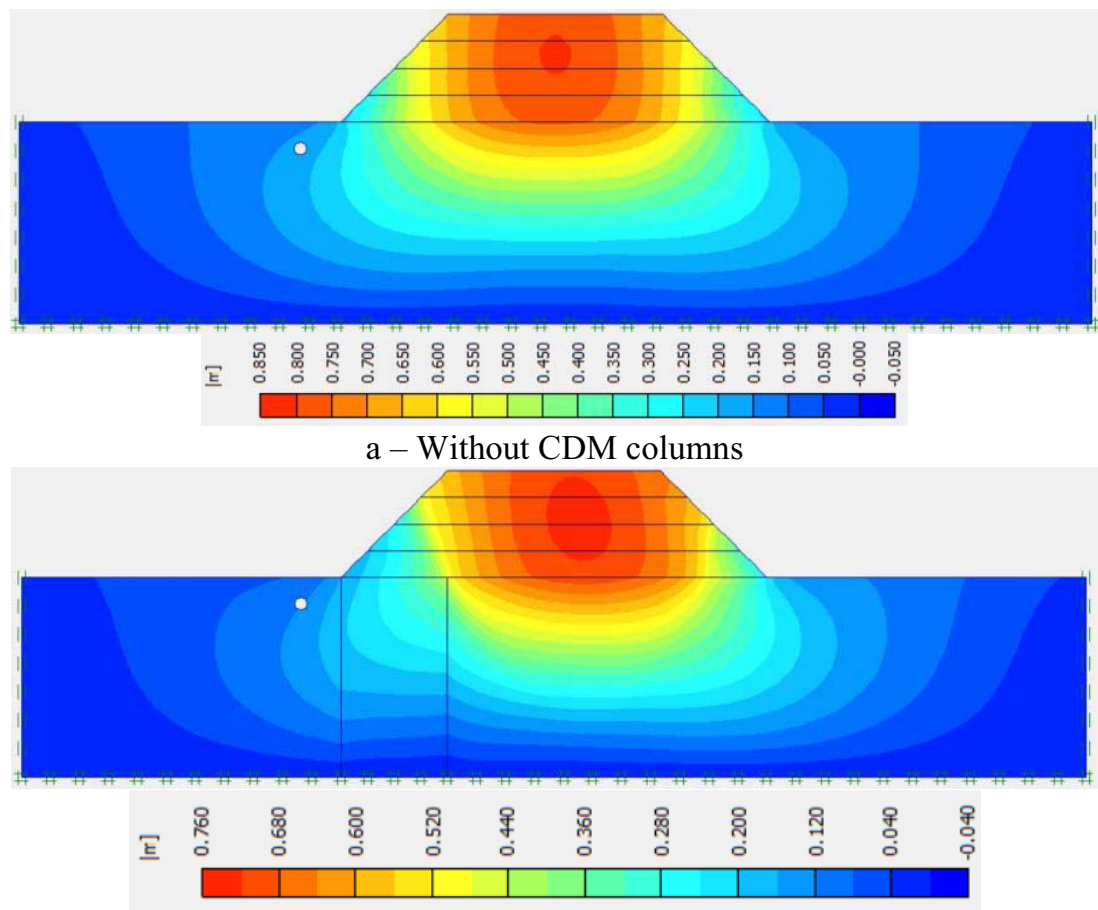

b - With CDM columns

Fig. 5. Total displacement contours

Further investigation on the absolute values of ground lateral displacement $\Delta \mathrm{x}$ along the depth or y direction (i.e. I-I section Fig.1 and 3). The improvement of the proposed method can be observed with the maximum of $19 \mathrm{~cm}$ displacement in the case of CDM column absence reduced to $13 \mathrm{~cm}$ with the reinforcement in the soft soil.

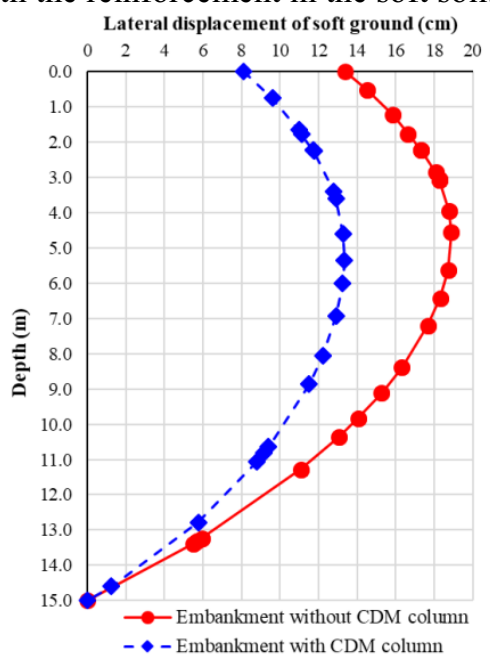

Fig. 6. Lateral displacement of soft ground at the toe of the embankment (secsion I-I)

Fig.7 illustrates the moment distribution in pipe with the maximum moment reduced from $1.45 \mathrm{kNm} / \mathrm{m}$ to $1.08 \mathrm{kNm} / \mathrm{m}$ or the ring bending moment reduces to 25.52 percent. This value in the case of minimum is 27.14 percent. This reduction of the internal force is a clue of the mitigation of risk of pipe falure due to the ring bending from soil deformation due to the construction of the embankment. 


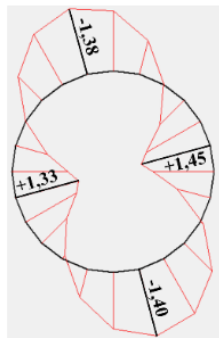

a - Without CDM columns

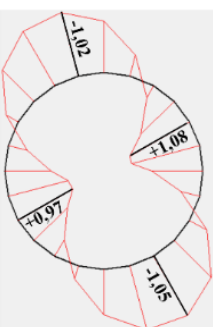

b - With CDM columns

Fig. 7. Bending moment diagram of buried pipe $(\mathrm{kNm} / \mathrm{m})$

Table 2 provides additional information obtained from the comparison between the cases of with and without CDM columns. It can be seen that vertical displacement, $\delta_{\mathrm{x}}{ }^{\max }$, internal forces (i.e. maximum moment, axial load and shear force or $\mathrm{M}_{\max }, \mathrm{N}_{\max }$ and $\mathrm{Q}_{\max }$, respectively) and maximum stress, $\sigma_{\max }$, of the pipe is reduced significantly.

Table 2. Comparison between the control case and the case without CDM columns

\begin{tabular}{|l|c|c|c|}
\hline Variable & Unit & Without CDM columns & With CDM columns \\
\hline$\delta_{\mathrm{x}}{ }^{\max }$ & $\mathrm{cm}$ & 17,32 & 11,81 \\
\hline $\mathrm{M}_{\max }$ & $\mathrm{kNm} / \mathrm{m}$ & 1,45 & 1,08 \\
\hline $\mathrm{N}_{\max }$ & $\mathrm{kN} / \mathrm{m}$ & 27,62 & 24,14 \\
\hline $\mathrm{Q}_{\max }$ & $\mathrm{kN} / \mathrm{m}$ & 6,75 & 4,94 \\
\hline$\sigma_{\max }$ & $\mathrm{kPa} / \mathrm{m}$ & 55365,27 & 41342,63 \\
\hline
\end{tabular}

\subsection{Parametric study}

This section provides a selective parametric study of 3 input variables to the maximum lateral displacement, $\delta_{\mathrm{x}}{ }^{\max }$, and maximum stress, $\sigma_{\max }$, due to the ring bending in pipe. The observed variables are: relative distance of pipe to the toe of slope, normalized by pipe outside diameter, $\mathrm{L}_{\mathrm{p}} / \mathrm{D}$; the $\mathrm{m}$ ratio; and the length of the CDM columns, $\mathrm{L}$.

Intuitively, the further the pipe is installed, the less lateral displacement it will be. Fig.8a has quantified this by the reduction from $20 \mathrm{~cm}$ to $4 \mathrm{~cm}$ for pipe placed with $\mathrm{L}_{\mathrm{p}} / \mathrm{D}=1$ to 20 , respectively. The corresponding $\mathrm{M}_{\max }$ of such case is dramatically reduced from $85 \mathrm{kNm} / \mathrm{m}$ to $28 \mathrm{kNm} / \mathrm{m}$ with a parabolic relationship with $\mathrm{L}_{\mathrm{P}} / \mathrm{D}$.

In Fig8.d, the $m$ ratio has a significant effect to $M_{\max }$ with the reduction of this variable from around $50 \mathrm{kNm} / \mathrm{m}$ to about $41 \mathrm{kNm} / \mathrm{m}$. However, the lateral displacement of the pipe, $\delta_{\mathrm{x}}{ }^{\text {max }}$, is minor changed from $14 \mathrm{~cm}$ to less than $12 \mathrm{~cm}$. Thus, increasing the number of CDM columns in a unit area is not an appropriate solution to reduce the lateral displacement of the pipe.

Effect of the length of the CDM columns, L, to the displacement and maximum moment in pipe is significant with the increase of $\mathrm{L}$ from $1.5 \mathrm{~m}$ to $15 \mathrm{~m}$, leading to the reduction of $\delta_{\mathrm{x}}{ }^{\max }$ from $17.8 \mathrm{~cm}$ to $11,81 \mathrm{~cm}$ and $\mathrm{M}_{\max }$ from $61 \mathrm{kNm} / \mathrm{m}$ to $41 \mathrm{kNm} / \mathrm{m}$. The point with minimum $\sigma_{\max }$ is interestingly appeared at the middle of the range where $\mathrm{L}=5 \mathrm{~m}$ and $\sigma_{\max }=$ $40 \mathrm{kNm} / \mathrm{m}$. 
a)

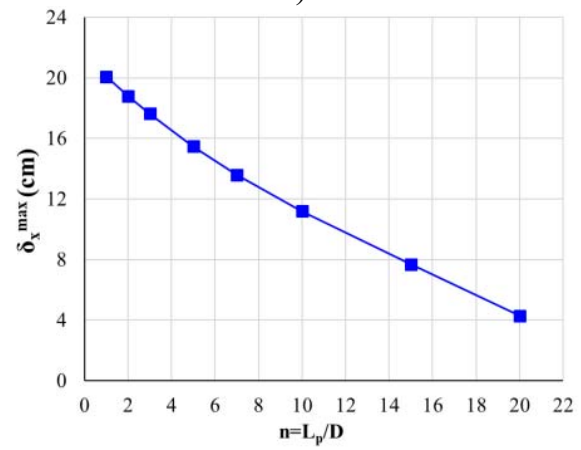

c)

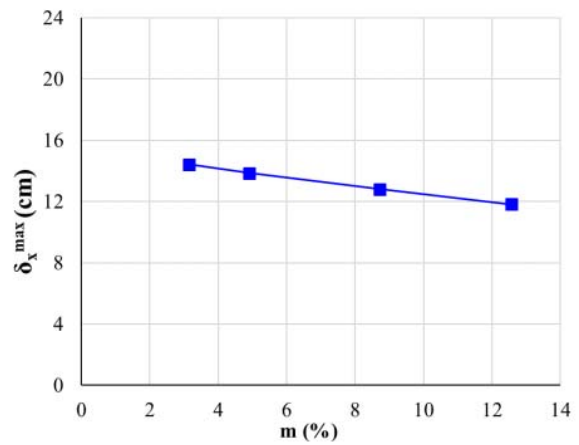

e)

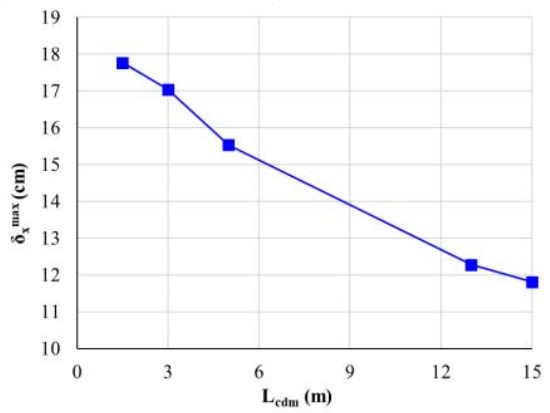

b)

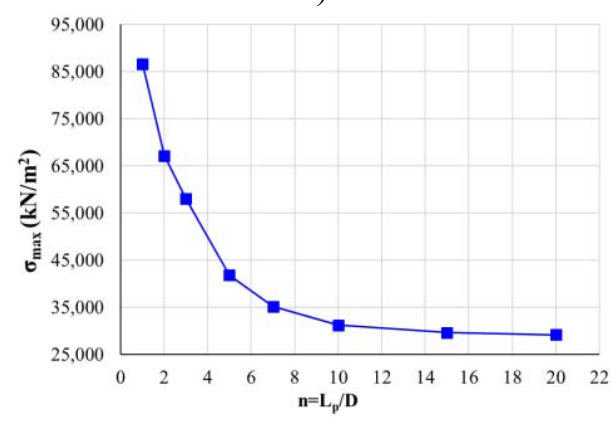

d)

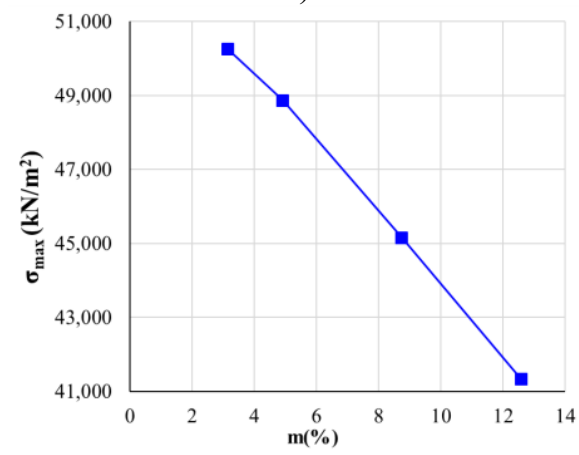

f)

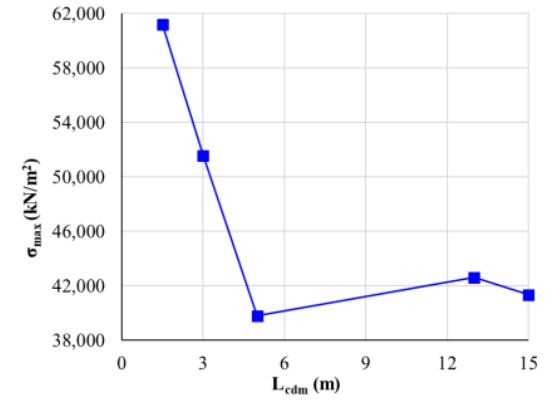

Fig. 8. Parametric study of critical input variables to the lateral displacement (a, c, e) and stress (b, d, f) of the buried pipe.

\section{Conclusion}

The study aims to model the embankment on the soft soil reinforced by the CDM columns installed to eliminate the lateral displacement of the buried adjacent pipe. The proposed model is numerically analysis by a 2D FE model. For the simplification purpose, the equivalent soil which considers soft soil and CDM columns as a type of soil is applied.

The positive effect of the appearance of the CDM column system has been investigated with the maximum displacement of the pipe significantly reduced from $17.32 \mathrm{~cm}$ to $11.81 \mathrm{~cm}$ coupling with the decrease of moment in pipe is up to 27.14 percent.

Selective parametric study has revealed the critical effect of the relative distance of pipe to the slope toe to the displacement and the maximum stress in pipe due to the ring bending. The length of CDM columns has a significant influence to the interested outputs. 
Meanwhile, the ratio of column section area per plan area of equivalent soil block has minor effect to lateral displacement but significant influence to the maximum stress in pipe.

Various further works can be developed from the current study such as the improvement of the model in 3-dimensions to account to the longitudinal stress of the problem coupling with the ring bending stress.

This research is funded by Vietnam National Foundation for Science and Technology Development (NAFOSTED) under Grant number: 107.02-2020.04.

\section{References}

1. Zhang, J., Y. Xiao, and Z. Liang, Mechanical behaviors and failure mechanisms of buried polyethylene pipes crossing active strike-slip faults. Composites Part B: Engineering, 2018. 154: p. 449-466.

2. Shi, J., Y. Wang, and Y. Chen, A simplified method to estimate curvatures of continuous pipelines induced by normal fault movement. Canadian Geotechnical Journal, 2018. 55(3): p. 343-352.

3. Ni, P., S. Mangalathu, and Y. Yi, Fragility analysis of continuous pipelines subjected to transverse permanent ground deformation. Soils and Foundations, 2018. 58(6): p. 14001413.

4. Peng, S., W. Liao, and E. Liu, Pipe-soil interaction under the rainfall-induced instability of slope based on soil strength reduction method. Energy Reports, 2020. 6: p. $1865-1875$.

5. Li, X., T. Wang, and Y. Yang, An Investigation into the Tunnel-Soil-Pipeline Interaction by In Situ Measured Settlements of the Pipelines. Advances in Civil Engineering, 2020. 2020.

6. Zhang, Z., M. Zhang, and Q. Zhao, A simplified analysis for deformation behavior of buried pipelines considering disturbance effects of underground excavation in soft clays. Arabian Journal of Geosciences, 2015. 8(10): p. 7771-7785.

7. Hong, W.P. and S. Hong, Piled embankment to prevent damage to pipe buried in soft grounds undergoing lateral flow. Marine Georesources \& Geotechnology, 2017. 35(5): p. 719-729.

8. Huang, Z., K. Ziotopoulou, and G.M. Filz, 3D numerical limiting case analyses of lateral spreading in a column-supported embankment. Journal of Geotechnical and Geoenvironmental Engineering, 2019. 145(11): p. 04019096.

9. Hong, W.P., J.H. Kim, and S. Hong, Role of piles in mitigating the movement of pipes in soft grounds during embankment loading. Marine Georesources \& Geotechnology, 2019. 37(9): p. 1019-1031.

10. Liyanage, K. and A.S. Dhar, Stresses in cast iron water mains subjected to non-uniform bedding and localised concentrated forces. International Journal of Geotechnical Engineering, 2018. 12(4): p. 368-376.

11. Balkaya, M., I.D. Moore, and A. Sağlamer, Study of nonuniform bedding support because of erosion under cast iron water distribution pipes. Journal of geotechnical and geoenvironmental engineering, 2012. 138(10): p. 1247-1256.

12. Karamanos, S.A., Mechanical behavior of steel pipe bends: an overview. Journal of Pressure Vessel Technology, 2016. 138(4).

13. Rashid, A.S.A., A.R. Bunawan, and K.N.M. Said, The deep mixing method: bearing capacity studies. Geotechnical and Geological Engineering, 2017. 35(4): p. 1271-1298.

14. Pourakbara, S., Deep mixing columns. Pertanika Journal of Scholarly Research Reviews, 2015. 1(1). 
15. Navin, M.P., Stability of embankments founded on soft soil improved with deep-mixingmethod columns. 2005, Virginia Tech.

16. Ou, C.-Y., T.-S. Wu, and H.-S. Hsieh, Analysis of deep excavation with column type of ground improvement in soft clay. Journal of Geotechnical engineering, 1996. 122(9): p. 709-716.

17. Brinkgreve, R., E. Engin, and W. Swolfs, PLAXIS 3D 2013 user manual. Plaxis bv, Delft, 2013.

18. Technology, M.o.S., Stabilization of Soft Soil by the Soil Cement Column Method, in TCXDVN 385: 2006. 2006. 